\title{
MAMPUKAH PROVINSI PAPUA MENCAPAI TUJUAN PERTAMA DARI SDGs?
}

\author{
Studi Kasus di Provinsi Papua \\ Mampukah Provinsi Papua Mencapai Tujuan Pertama dari SDGs? (Is Papua Capable to \\ Reach the First Goals of SDGs?)
}

\author{
Septian Karangan Kambubuy ${ }^{1}$, Budiasih² \\ Badan Pusat Statistik ${ }^{1}$ \\ Politeknik Statistika STIS 2
}

JIn. Kebun Sayur No. 9, RT/RW 004/015, Kec. Jatinegara, Jakarta Timur

E-mail: 14.8377@stis.ac.id

\begin{abstract}
ABSTRAK
Tujuan pertama dari SDGs adalah mengentaskan segala bentuk kemiskinan dimana pun. Provinsi Papua selama periode 2010-2017 merupakan provinsi dengan persentase penduduk miskin tertinggi di Indonesia. Selain itu, dalam periode yang sama provinsi Papua juga merupakan provinsi dengan tingkat kedalaman dan keparahan kemiskinan tertinggi di Indonesia. Kedalaman kemiskinan ditunjukan oleh adanya gap antara pengeluaran perkapita penduduk miskin dengan garis kemiskinan. Sedangkan, keparahan kemiskinan ditunjukan oleh adanya gap pengeluaran perkapita yang terjadi diantara penduduk miskin. Penelitian ini bertujuan untuk menganalisis faktor-faktor yang mempengaruhi kedalaman dan keparahan kemiskinan di provinsi Papua. Model yang digunakan adalah regresi linier berganda dengan meggunakan data panel. Hasil penelitian menunjukan bahwa besarnya alokasi belanja pemerintah dalam bidang pendidikan dan perlindungan sosial berpengaruh signifikan dalam mengurangi kedalaman dan keparahan kemiskinan di provinsi Papua. Sebaliknya, besarnya alokasi belanja pemerintah dalam bidang kesehatan hanya berpengaruh signifikan dalam mengurangi keparahan kemiskinan di provinsi Papua. Kesimpulannya adalah pemerintah provinsi Papua belum mampu dalam menurunkan persentase penduduk miskin. Namun, baru mampu menurunkan gap antara pengeluaran perkapita penduduk miskin dengan garis kemiskinan, dan juga mengurangi ketimpangan pengeluaran perkepita diantara penduduk miskin.
\end{abstract}

Kata kunci: kedalaman kemiskinan, keparahan kemiskinan, analisis regresi data penel

\section{ABSTRACT}

The first goal of the SDGs is to eradicate all forms of poverty everywhere. Papua Province during the period 2010-2017 was province with the highest percentage of poor population in Indonesia. In addition, in the same period the province of Papua was also the province with the highest level and severity of poverty in Indonesia. Poverty is caused by the gap between poor per capita population and the poverty line. Meanwhile, the severity of poverty caused by the gap published per capita that occurs among the poor population. This study aims to analyze the factors that influence the increase and severity of poverty in Papua province. Model used is multiple linear regression using panel data. Results show how the contribution of government spending in education and social protection is significant in reducing poverty levels in Papua. Ignoring government spending on health has only a significant impact in reducing the severity of poverty in Papua province. The conclusion is that the Papua provincial government has not been able to reduce the percentage of the poor population. However, it was only able to reduce gap between addition of poor population with poverty line, and also reduce disparity in population expenditure.

Keywords: The Gap of Poverty, The Severity of Poverty, Regression of Panel Data

\section{PENDAHULUAN Latar Belakang}

Kemiskinan merupakan masalah yang dihadapi oleh hampir atau bahkan semua negara didunia. Dalam tujuan pertama Suistanabel Development Goals (SDGs) yang menyatakan "mengentaskan segala bentuk kemiskinan dimana pun", menunjukan kemiskinan merupakan masalah yang serius dan perlu diatasi dengan cepat karena menyakut pada kesejahteraan setiap orang. 
Indonesia merupakah salah satu negara yang ikut serta melaksanakan tujuan SDGs dalam pengentasan kemiskinan. Indonesia sendiri memiliki sejarah yang panjang mengenai masalah kemiskinan, dimana kemiskinan di Indonesia mengalami pemusatan pada wilayah timur dengan provinsi Papua sebagai provinsi dengan persentase penduduk miskin tertinggi yaitu sebesar 27,76 persen pada tahun 2017. Selain itu, provinsi Papua juga merupakan provinsi dengan indeks kedalman dan keparahan kemiskinan tertinggi jika dibandingkan dengan provinsi lainnya yaitu masing-masing sebesar 7,50 dan 2,83. Alasan mengapa kemiskinan diprovinsi Papua dari tahun ke tahun sulit untuk mengalami penurunan secara signifikan adalah karena terdapat kesenjangan yang besar yang ditunjukkan dari besarnya indeks kedalaman dan keparahan kemiskinan yang dimiliki provinsi Papua. Untuk itu, agar provinsi Papua dapat mencapai tujuan pertama SDGs yaitu mengentaskan kemiskinan maka kesenjangan yang ditunjukkan melalui indeks kedalaman dan keparahan kemiskinan perlu diatasi.

\section{METODE}

\section{Ruang Lingkup Penelitian}

Penelitian yang diakukan berlokus pada provinsi Papua dengan unit observasinya adalah kabupaten kota. Varibel-varibel independent yang digunakan dalam penelitian ini adalah meliputi belanja pemerintah menurut fungsi kesehatan, pendidikan, dan perlindungan sosial, dan juga selain itu menggunakan lagged pertama dari indeks kedalaman dan keparahan kemiskinan. Sedangkan variabel dependen yang digunakan adalah meliputi indeks kedalaman kemiskinan dan indeks keparahan kemiskinan. Kemudian pada penelitian ini metode analisis yang digunakan adalah analisis regresi data panel. Data yang digunakan merupakan data panel per kabupaten kota di provinsi Papua dari tahun 2010-2017. Data tersebut bersumber dari Badan Pusat Statistik dan Direktorat Jederal Perimbangan Keuangan.

\section{Analisis Regresi Data Panel}

Data panel adalah gabungan dari dua jenis data, yaitu data cross section dan data time series. Secara umum model yang digunakan dalam analisis data panel dapat dinyatakan sebagai berikut

$$
y_{i t}=\beta_{1}+\beta_{2} x_{1 i t}+\cdots+\beta_{k} x_{k i t}+u_{i t}
$$

dimana:

$y_{i t}=$ variabel dependen pada unit cross-section ke-i dan periode ke-t

$\beta_{1}=$ intersep

$\alpha_{i}=$ efek individu

$\beta_{k}=$ slope untuk variabel independen ke-k

$x_{k i t}=$ variabel independent ke-k pada unit cross-section ke-i dan periode ke-t

$u_{i t}=$ error komposit, dimana $u_{i t}=\alpha_{i}+\varepsilon_{i t}$

$\varepsilon_{i t}=$ error regresi pada unit cross-section ke i untuk periode ke-t; $\varepsilon_{i t} \sim N\left(0, \sigma_{\varepsilon}^{2}\right)$

$\mathrm{i}=1,2 \ldots, \mathrm{N}$, menunjukkan unit cross-section

$\mathrm{t}=1,2, \ldots, \mathrm{T}$, menunjukkan unit time series

$\mathrm{k}$ = banyaknya parameter

\section{Estimasi Model Data Panel}

Menurut Gujarati (2008), dalam analisis regresi data panel terdapat tiga pendekatan yang digunakan dalam melakukan estimasi, yaitu pendekatan Common Effect Model (CEM), pendekatan Fixed Effect Model(FEM), dan pendekatan Random Effect Model(REM).

a. Common Effect Model (CEM) merupakan pendekatan mengasumsikan bahwa tidak terdapat perbedaan antar unit cross-section maupun antar periode waktu, sehingga hal ini akan menyamarkan heterogenitas yang kemungkinan ada diantara unit cross-section. Common Effect Mode/ dinyatakan sebagai berikut: 
$y_{i t}=\beta_{1}+\beta_{2} x_{1 i t}+\cdots+\beta_{k} x_{k i t}+\varepsilon_{i t}$

dimana:

$y_{i t}=$ variabel dependen pada unit cross-section ke-i dan periode ke-t

$\beta_{1}=$ intersep

$\beta_{k}=$ slope untuk variabel independen ke-k

$x_{k i t}=$ variabel independent ke-k pada unit cross-section ke-i dan periode ke-t

$\varepsilon_{i t}=$ error regresi pada unit cross-section ke i untuk periode ke-t; $\varepsilon_{i t} \sim N\left(0, \sigma_{\varepsilon}^{2}\right)$

$\mathrm{i}=1,2 \ldots, \mathrm{N}$, menunjukkan unit cross-section

$\mathrm{t}=1,2, \ldots, \mathrm{T}$, menunjukkan unit time series

$\mathrm{k}=$ banyaknya parameter

b. Fixed Effect Model (FEM) merupakan pendekatan yang menunjukan adanya kemungkinan perbedaan pada intersep antar unit cross-section. Fixed Effect Model dinyatakan sebagai berikut:

$y_{i t}=\beta_{1}+\beta_{2} x_{1 i t}+\cdots+\beta_{k} x_{k i t}+u_{i t} \cdots \cdots \cdots \cdots$
$y_{i t}=\beta_{1}+\beta_{2} x_{1 i t}+\cdots+\beta_{k} x_{k i t}+\left(\alpha_{i}+\varepsilon_{i t}\right)$.
$y_{i t}=\left(\alpha_{i}+\beta_{1}\right)+\beta_{2} x_{1 i t}+\cdots+\beta_{k} x_{k i t}+\varepsilon_{i t}$.
$y_{i t}=\beta_{1 i}+\beta_{2} x_{1 i t}+\cdots+\beta_{k} x_{k i t}+\varepsilon_{i t} \cdots \cdots \cdots \cdots$

dimana:

$y_{i t}=$ variabel dependen pada unit cross-section ke-i dan periode ke-t

$\beta_{1}=$ intersep

$\alpha_{i}=$ efek individu

$\beta_{1 i}=$ intersep individu ke-i

$\beta_{k}=$ slope untuk variabel independen ke-k

$x_{k i t}=$ variabel independent ke-k pada unit cross-section ke-i dan periode ke-t

$u_{i t}=$ error komposit, dimana $u_{i t}=\alpha_{i}+\varepsilon_{i t}$

$\varepsilon_{i t}=$ error regresi pada unit cross-section ke i untuk periode ke-t; $\varepsilon_{i t} \sim N\left(0, \sigma_{\varepsilon}^{2}\right)$

$\mathrm{i}=1,2 \ldots, \mathrm{N}$, menunjukkan unit cross-section

$\mathrm{t}=1,2, \ldots, \mathrm{T}$, menunjukkan unit time series

$\mathrm{k}=$ banyaknya parameter

C. Random Effect Model (REM) menggunakan residual yang diduga memiliki hubungan antar waktu dan antar objek. Random Effect Mode/ dinyatakan sebagai berikut:

$y_{i t}=\beta_{1}+\beta_{7} x_{1 i t}+\cdots+\beta_{k} x_{k i t}+\left(\alpha_{i}+\varepsilon_{i t}\right)$.

$\alpha_{i}+\varepsilon_{i t}=u_{i t}$

$y_{i t}=\beta_{1}+\beta_{2} x_{1 i t}+\cdots+\beta_{k} x_{k i t}+u_{i t}$

dimana:

$y_{i t}=$ variabel dependen pada unit cross-section ke-i dan periode ke-t

$\beta_{1}=$ intersep

$\alpha_{i}=$ efek individu

$\beta_{k}=$ slope untuk variabel independen ke-k

$x_{k i t}=$ variabel independent ke-k pada unit cross-section ke-i dan periode ke-t

$u_{i t}=$ error komposit

$\varepsilon_{i t}=$ error regresi pada unit cross-section ke i untuk periode ke-t; $\varepsilon_{i t} \sim N\left(0, \sigma_{\varepsilon}^{2}\right)$

$\mathrm{i}=1,2 \ldots, \mathrm{N}$, menunjukkan unit cross-section

$\mathrm{t}=1,2, \ldots, \mathrm{T}$, menunjukkan unit time series

$\mathrm{k}$ = banyaknya parameter 


\section{Landasan Teori}

\section{Kemiskinan}

Dalam melihat kondisi kemiskinan, Badan Pusat Statistik menggunakan acuan berdasarkan tiga indicator yaitu Head Count Index $\left(\mathrm{HCI}-\mathrm{P}_{0}\right)$ merupakan persentase penduduk miskin yang berada dibawah garis kemiskinan, indeks Kedalaman Kemiskinan (Poverty Gap Index-P1) merupakan ukuran rata-rata kesenjangan pengeluaran perkapita penduduk miskin terhadap garis kemiskinan, indeks Keparahan Kemiskinan (Poverty Severity Index-P2) merupakan gambaran mengenai penyebaran pengeluaran diantara penduduk miskin.

Badan Pusat Statistik menggunakan acuan dari Foster-Greer-Thorbecke (1984) dalam merumuskan ketiga ukuran kemiskinan tersebut.

$$
P_{\alpha}=\frac{1}{n} \sum_{i=1}^{q}\left[\frac{z-y_{i}}{z}\right]^{\alpha}
$$

dimana:

$a=0,1,2$

$\mathrm{z}=$ Garis Kemiskinan

$y_{i}=$ Rata-rata pengeluaran perkapita sebulan penduduk yang beada dibawah garis kemiskinan

$\mathrm{q}=$ Jumlah penduduk yang berada dibawah garis kemiskinan

$\mathrm{n}=$ Jumlah penduduk

\section{Belanja Pemerintah Daerah Menurut Fungsi Kesehatan}

Belanja pemerintah daerah menurut fungsi kesehatan merupakan anggaran yang bersumber dari APBN yang dikeluarkan pemerintah daerah untuk mencapai tujuan pembangunan dibidang kesehatan, dimana tujuan tersebut adalah untuk mencapai derajat kesehatan yang terus membaik.

\section{Belanja Pemerintah Daerah Menurut Fungsi Pendidikan}

Belanja pemerintah daerah menurut fungsi pendidikan merupakan anggaran yang bersumber dari APBN yang dikeluarkan pemerintah daerah dengan tujuan untuk membiayai penyelenggaraan pendidikan yang menjadi tanggung jawab pemerintah.

\section{Belanja Pemerintah Daerah Menurut Fungsi Perlindungan Sosial}

Belanja pemerintah daerah menurut fungsi perlindungan sosial merupakan anggaran yang bersumber dari APBN yang dikeluarkan pemerintah daerah dengan tujuan untuk menjaga agar kemiskinan pada suatu daerah dapat menurun secara konsisten.

\section{Pengaruh Alokasi Belanja Pemerintah Terhadap Kemiskinan}

Dalam teori perilaku konsumen terdapat tiga hal yang menjadi penyusunnya, dimana ketiga hal tersebut meliputi budget constraint, preferensi konsumen, dan optimisasi. Dengan mengaplikasikan teori periaku konsumen, maka kita dapat menjelaskan penggunaan pendapatan pemerintah yang dialokasikan untuk memenuhi kombinasi belanja pemerintah yang dapat memberikan kepuasan maksimal. Pada bagian ini menunjukan bahwa dalam menjalankan kebijakankebijakan yang telah dibentuk pemerintah, maka tentunya pemerintah perlu melakukan penyesuaian dengan pendapatan yang ada. Hal ini perlu dilakukan agar pengeluaran untuk belanja pemerintah tidak melebihi batasan pendapatan atau budget constrain dari pemerintah. Kemudian, pada bagian kedua menjelaskan tentang preferensi konsumen. Pada bagian ini menunjukan bahwa, indifference curve yang dimiliki pemerintah merupakan semua kombinasi produk-produk dalam market basket yang memberikan pemerintah tingkat kepuasan yang sama. Kemudian pada bagian selanjutnya menjelaskan tentang optimisasi. Pada bagian ini menunjukan bahwa dalam mencapai kepuasan maksimal, maka pemerintah perlu menyesuaikan indifference curve-nya dengan budget line yang dimiliki pemerintah. Penyesuaian yang dimaksudkan ini adalah bahwa total pengeluaran untuk kombinasi belanja pemerintah harus disesuaikan dengan pendapatan, dimana tidak melebihi pendapatan yang ada. 
Tercapainya kepuasan pemerintah secara maksimal dapat diartikan sebagai suatu keadaan dimana tercapainya tujuan dari pemerintah. Dalam hal ini, tercapainya tujuan dari pemerintah diperlihatkan sebagai kondisi dimana perekonomian suatu wilayah semakin membaik. Semakin membaiknya kondisi perekonomian ini, disebabkan oleh dampak dari alokasi pendapatan untuk belanja pemerintah yang tepat sasaran.

Menurut Keynes (1935) dalam bukunya yang berjudul " The General Theory of Employment, Interest, and Money' menyatakan bahwa melalui pengelolaan pengeluaran pemerintah dalam kebijakan fiskal merupakan suatu cara dalam mempengaruhi jalannya perekonomian, dimana ini tentunya efektif dalam meningkatkan output dan menurunkan pengangguran. Peningkatan permintaan output yang disebabkan oleh pengeluaran pemerintah tentunya akan meningkatkan penyerapan tenaga kerja, sehingga ini akan menurunkan jumlah pengangguran yang ada. Semakin banyak jumlah penduduk yang telah memiliki pekerjaan, maka tentunya mereka akan memliki pendapatan yang cukup untuk memenuhi kebutuhan dasar mereka. Dengan demikian, dapat dikatakan bahwa dengan menurunnya jumlah pengangguran, maka ini akan berpengaruh pada penurunan angka kemiskinan diwilayah tersebut.

\section{Kerangka Pikir}

Indeks Kedalaman Kemiskinan (P1)

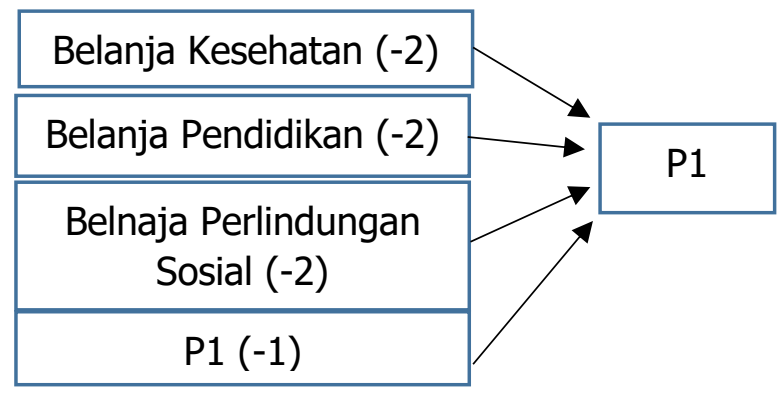

Indeks Keparahan Kemiskinan (P2)

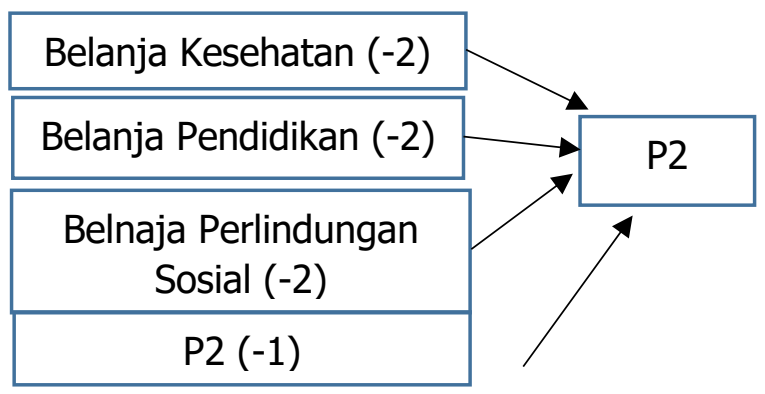

\section{Tahapan-tahapan analisis}

Langkah-langkah analisis regresi data panel adalah sebagai berikut: (1) Menyusun data yang berisi nama kabupaten kota, tahun, variabel dependen dan variabel independent. (2) Selanjutnya, mengestimasi model yang terbaik di antara common effect model, fixed effect model, dan random effect model. (3) Melakukan uji chow untuk mengetahui model mana yang lebih baik antara common effect mode/ dan fixed effect model. Jika keputusannya adalah fixed effect model, maka melakukan uji selanjutnya yaitu uji hausman. Sedangkan jika keputusannya adalah common effect model, maka dilanjutkan dengan uji BP-LM. Uji hausman digunakan untuk mengetahui model mana yang lebih baik antara random effect modeldan fixed effect model, dan sedangkan uji BP-LM digunakan untuk mengetahui model mana yang lebih baik antara common effect mode/dan rendom effect model. (4) Jika model yang terpilih common effect model, maka selanjutnya pengujian asumsi klasik. Jika model yang terpilih random effect model, maka selanjutnya pengujian asumsi klasik yang dilakukan hanya uji normalitas, dan multikolinearitas. Jika keputusannya fixed effect model, maka perlu memeriksa heteroskedastisitas dengan menggunakan struktur varians-kovarians residual serta memeriksa cross-sectional correlation dengan menggunakan uji Lagrange Multiplier (uji LM). Kemudian menguji asumsi klasik seperti asumsi normalitas dan multikolinearitas. (5) Melakukan uji keberartian model dengan melihat nilai Adjusted $R$-square, hasil uji F dan uji t. (7) Melakukan interpretasi terhadap model yang terpilih.

\section{HASIL DAN PEMBAHASAN}

\section{Penduduk Miskin}




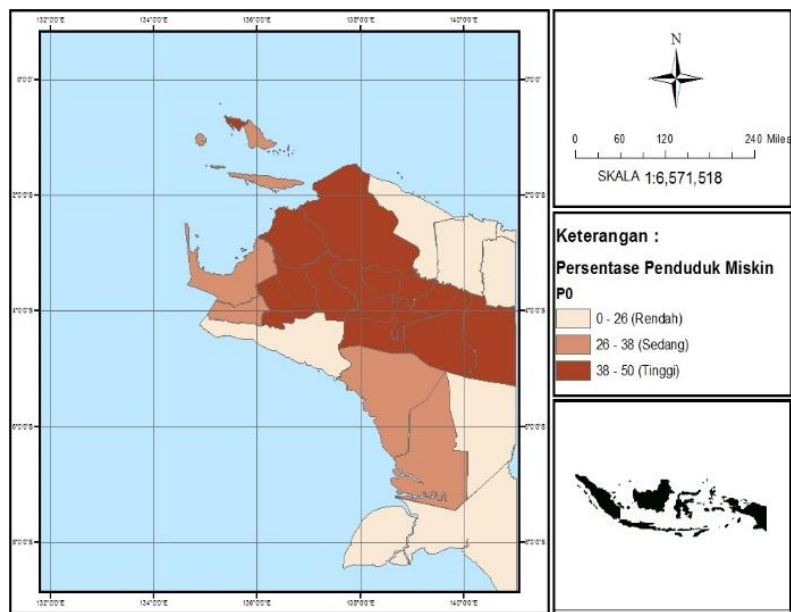

Gambar 1. Peta persentase penduduk miskin kabupaten kota di Papua tahun 2010

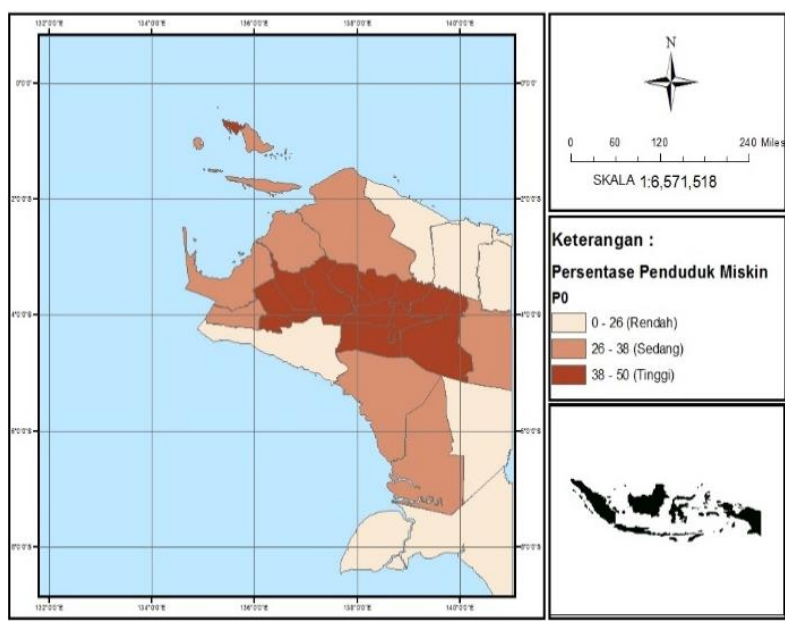

Gambar 2. Peta persentase penduduk miskin kabupaten kota di Papua tahun 2017

Perbandingan persentase penduduk miskin untuk setiap kabupaten kota di Papua pada tahun 2010 dengan 2017 menunjukan adanya perubahan. Perubahan yang terjadi adalah terdapat beberapa kabupaten yang mengalami penurunan persentase penduduk miskin dari kategori tinggi ke sedang. Kemudian, jika diperhatikan persentase penduduk miskin dengan kategori tinggi dari tahun 2010 hingga 2017 mengalami pergerakan yang memusat pada kabupaten kota diwilayah bagian pegunungan.

\section{Kedalaman Kemiskinan}

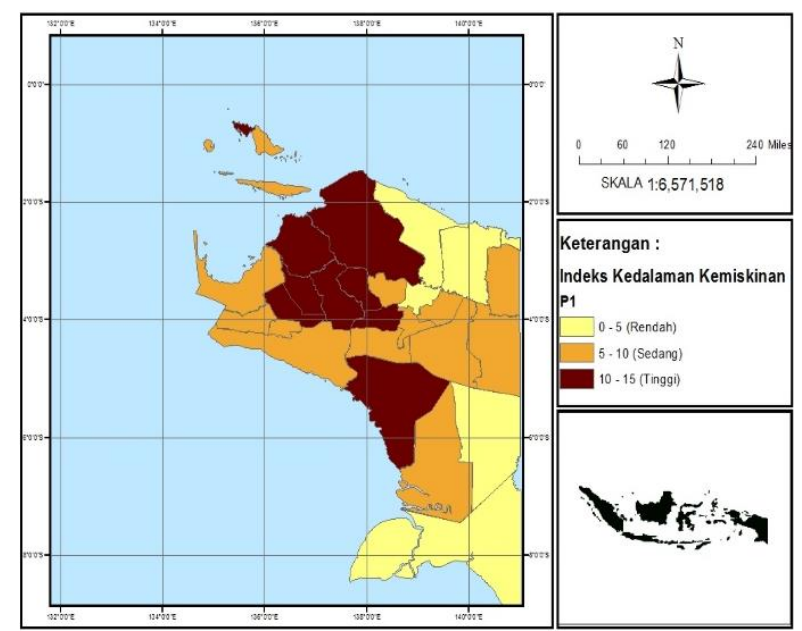

Gambar 3. Peta indeks kedalaman kemiskinan kabupaten kota di Papua tahun 2010

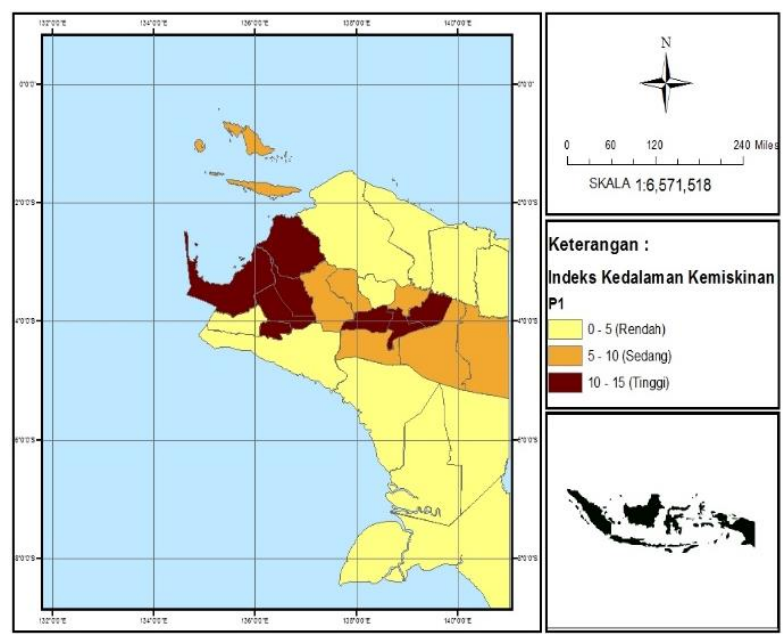

Gambar 4. Peta indeks kedalaman kemiskinan kabupaten kota di Papua tahun 2017

Perbandingan indeks kedalaman kemiskinan untuk setiap kabupaten kota di Papua pada tahun 2010 dengan 2017 menunjukan adanya perubahan. Perubahan yang terjadi adalah terdapat beberapa kabupaten yang mengalami penurunan indeks kedalaman kemiskinan dari kategori tinggi ke sedang, kategori tinggi ke rendah, dan kategori sedang ke rendah. Namun, ada juga beberapa kabupaten yang meningkat dari kategori sedang ke tinggi dan kategori rendah ke sedang. Kemudian, jika diperhatikan indeks kedalaman kemiskinan dengan kategori sedang dan tinggi dari tahun 2010 hingga 2017 mengalami pergerakan yang memusat pada kabupaten kota diwilayah bagian pegunungan. 


\section{Keparahan Kemiskinan}

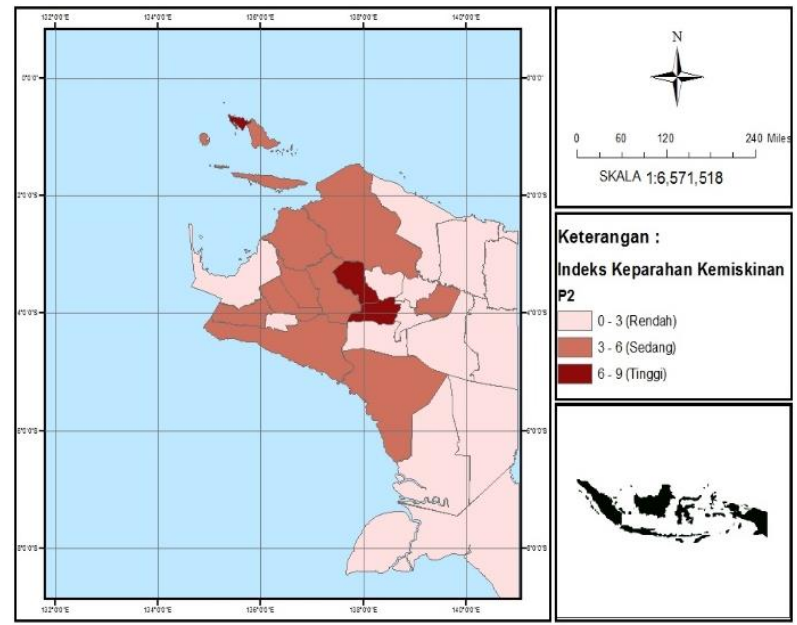

Gambar 5. Peta indeks keparahan kemiskinan kabupaten kota di Papua tahun 2010

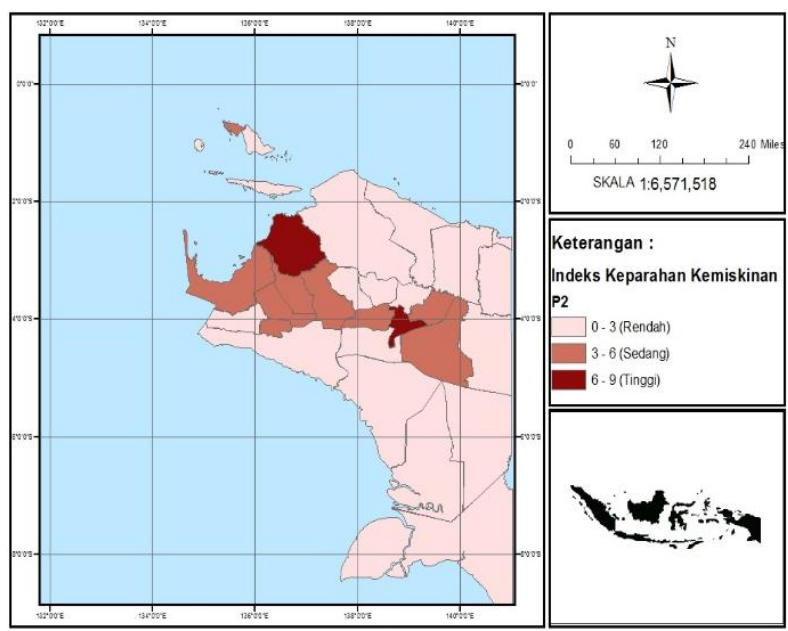

Gambar 6. Peta indeks keparahan kemiskinan kabupaten kota di Papua tahun 2017

Perbandingan indeks keparahan kemiskinan untuk setiap kabupaten kota di Papua pada tahun 2010 dengan 2017 menunjukan adanya perubahan. Perubahan yang terjadi adalah terdapat beberapa kabupaten yang mengalami penurunan indeks keparahan kemiskinan dari kategori tinggi ke sedang, kategori tinggi ke rendah, dan kategori sedang ke rendah. Namun, ada juga beberapa kabupaten yang meningkat dari kategori sedang ke tinggi dan kategori rendah ke sedang. Kemudian, jika diperhatikan indeks keparahan kemiskinan dengan kategori sedang dan tinggi dari tahun 2010 hingga 2017 mengalami pergerakan yang memusat pada kabupaten kota diwilayah bagian pegunungan.

\section{Pemilihan Model Terbaik}

Dalam analisis data panel terdapat tiga jenis model, yaitu common effect model, fixed effect model, dan random effect model. Dalam pemilihan model diantara ketiga model tersebut maka perlu dilakukannya uji statistik yang sesuai.

1. Uji Chow digunakan untuk memilih model terbaik diantara common effect mode/dan fixed effect model. Pada model indeks kedalaman kemiskinan dilampiran diperoleh $p$-value dari F-statistik adalah sebesar 0,0000 , dimana hal ini menunjukan keputusan bahwa hipotesis nol ditolak karena nilai $p$-value dari F-statistik lebih kecil dari $a=0,05$. Berdasarkan hasil ini maka dapat disimpulkan bahwa model yang terpilih adalah fixed effect model. Pada model indeks keparahan kemiskinan dilampiran diperoleh $p$-value dari F-statistik adalah sebesar 0,0000, dimana hal ini menunjukan keputusan bahwa hipotesis nol ditolak karena nilai $p$-value dari F-statistik lebih kecil dari $a=0,05$. Berdasarkan hasil ini maka dapat disimpulkan bahwa model yang terpilih adalah fixed effect model.

2. Uji Hausman digunakan untuk memilih model terbaik diantara random effect model dan fixed effect model. Pada model indeks kedalaman kemiskinan dilampiran diperoleh $p$-value dari crosssection random adalah sebesar 0,0000, dimana hal ini menunjukan keputusan bahwa hipotesis nol ditolak karena nilai $p$-value cross-section random lebih kecil dari $a=0,05$. Berdasarkan hasil ini maka dapat disimpulkan bahwa model yang terpilih adalah fixed effect model. Pada model indeks keparahan kemiskinan dilampiran diperoleh $p$-value dari cross-section random adalah sebesar 0,0000, dimana hal ini menunjukan keputusan bahwa hipotesis nol ditolak karena nilai $p$-value dari cross-section random lebih kecil dari $\mathrm{a}=0,05$. Berdasarkan hasil ini maka dapat disimpulkan bahwa model yang terpilih adalah fixed effect model 


\section{Penentuan Metode Estimasi}

Fixed effect model pada umumnya menggunakan metode estimasi ordinary least square, namun pada beberapa kondisi tertentu fixed effect model dapat menggunakan beberapa metode estimasi lain. Ketika terdapat cross-sectional correlation pada fixed effect model maka metode estimasi yang dapat digunakan adalah metode Feasible Generalized Least Square (FGLS)/Seemingly Unrelated Regression (SUR).

Hasil uji LM pada model indeks kedalaman kemiskinan menunjukan keputusan tolak hipotesis nol, dimana nilai LM sebesar 19,9889 lebih besar dari $\chi_{0,05 ; 28}(16,9279)$ sehingga struktur varianscovarian residualnya bersifat heteroskedastik. Kemudian hasil uji LR menunjukan keputusan tolak hipotesis nol, dimana nilai $\lambda_{L M}$ sebesar 810,2639 lebih besar dari $\chi_{0,05 ; 406}(360,2931)$ sehingga hasil ini menyatakan bahwa terdapat cross-sectional correlation. Kemudian hasil uji LM pada model indeks keparahan kemiskinan menunjukan keputusan tolak hipotesis nol, dimana nilai LM sebesar 19,98892 lebih besar dari $\chi_{0,05 ; 28}(16,92788)$ sehingga hasil ini menyatakan bahwa struktur varians-covarian residualnya bersifat heteroskedastik. Kemudian hasil uji LR pada penelitian ini menunjukan keputusan tolak hipotesis nol, dimana nilai $\lambda_{L M}$ sebesar 830,6388 lebih besar dari $\chi_{0,05 ; 406}$ $(360,2931)$ sehingga hasil ini menyatakan bahwa terdapat cross-sectional correlation. Dari uji yang telah dilakukan, pada model indeks kedalaman dan keparahan kemiskinan struktur varianscovariansnya bersifat heteroskedasatik dan terdapat cross-sectional correlation, sehingga metode estimasi yang terpilih untuk kedua model adalah Feasible Generalized Least Square (FGLS)/Seemingly Uncorrelated Regression (SUR).

\section{Uji Keberartian Model}

1. Uji Koefisien Determinasi (R-Square). Pada model indeks kedalaman kemiskinan menunjukan nilai adjusted r-square sebesar 81,98 persen, sehingga dapat dikatakan bahwa variabel indeks kedalaman kemiskinan dapat dijelaskan oleh variabel belanja pemerintah menurut fungsi kesehatan lag kedua, menurut fungsi pendidikan lag kedua, menurut fungsi perlindungan sosial lag kedua dan variabel indeks kedalaman kemiskinan lag pertama sebesar 81,98 persen sedangkan 18,02 persen dijelaskan oleh variabel lain diluar penelitian. Sedangkan pada model indeks keparahan kemiskinan menunjukan nilai adjusted r-square sebesar 65,08 persen, sehingga dapat dikatakan bahwa variabel indeks keparahan kemiskinan dapat dijelaskan oleh variabel belanja pemerintah menurut fungsi kesehatan lag kedua, menurut fungsi pendidikan lag kedua, menurut fungsi perlindungan sosial lag kedua, dan indeks keparahan kemiskinan lag pertama sebesar 65,08 persen sedangkan 34,92 persen dijelaskan oleh variabel lain diluar penelitian.

2. Uji Simultan F. Hasil pengujian simultan F pada model indeks kedalaman kemiskinan menunjukan tolak hipotesis nol, dimana F-hitung dari model ini adalah sebesar 25,60 dan $p$-value bernilai 0,00. Sedangkan hasil pengujian simultan $F$ pada model indeks keparahan kemiskinan menunjukan tolak hipotesis nol, dimana F-hitung dari model ini adalah sebesar 11,08 dan $p$ value bernilai 0,00 . Berdasarkan hasil pengujian simultan $F$ pada kedua model maka dapat dikatakan bahwa variabel belanja pemerintah menurut fungsi kesehatan lag kedua, menurut fungsi pendidikan lag kedua, menurut fungsi perlindungan sosial lag kedua dan variabel indeks kedalaman kemiskinan lag pertama secara bersama-sama berpengaruh terhadap indeks kedalaman kemiskinan. Begitu juga sebaliknya dengan indeks keparahan kemiskinan.

3. Uji Partial (uji t). Dari masing-masing variabel independen yang berpengaruh signifikan pada variabel indeks kedalaman kemiskinan pada tingkat signifikansi 10 persen adalah variabel pendidikan(-2) dengan $p$-value $(0,00)$, dan variabel perlindungan sosial(-2) dengan $p$-value $(0,03)$. Sedangkan masing-masing variabel independen yang tidak berpengaruh signifikan pada variabel dependen adalah variabel kesehatan $(-2)$ dengan $p$-value $(0,11)$ dan variabel indeks kedalaman kemiskinan $(-2)$ dengan $p$-value $(0,52)$.

Dari masing-masing variabel independen yang berpengaruh signifikan pada variabel indeks keparahan kemiskinan pada tingkat signifikansi 10 persen adalah variabel kesehatan(-2) 
dengan $p$-value $(0,07)$, variabel pendidikan(-2) dengan $p$-value $(0,00)$, dan variabel perlindungan sosial $(-2)$ dengan $p$-value $(0,07)$. Sedangkan variabel independen yang tidak berpengaruh signifikan pada variabel dependen adalah variabel indeks keparahan kemiskinan $(-1)$ dengan $p$ value $(0,50)$.

\section{Uji Asumsi}

Model yang terpilih adalah model fixed effect mode/ dengan metode estimasi menggunakan seemingly Unrelated regression (SUR) maka dalam pengujian asumsi yang perlu dilakukan adalah asumsi normalitas dan multikolinearitas. Dalam Greene (2003) dijelaskan bahwa metode estimasi SUR yang digunakan sudah mengakomodasi kendala asumsi heteroskedasatik dan autokorelasi pada model.

1. Uji Normalitas. Hasil pengujian asumsi normalitas pada model menunjukan bahwa nilai statistik JB untuk model indeks kedalaman dan keparahan kemiskinan masing-masing adalah sebesar 5,37 dan 8,73 dengan $p$-value sebesar 0,068 dan 0,01, sehingga dengan tingkat signifikansi 1 persen menyatakan keputusan gagal tolak hipotesis nol yang berarti error berdistribusi normal.

2. Uji Multikolinearitas. Nilai VIF pada model indeks kedalaman kemiskinan untuk variabel kesehatan $(-2)$, pendidikan $(-2)$, perlindungan sosial $(-2)$ dan P1(-1) masing-masing adalah 1,$418743 ; 1,930085 ; 1,646592 ;$ dan 1,211027. Sedangkan nilai VIF pada model indeks keparahan kemiskinan untuk variabel kesehatan $(-2)$, pendidikan $(-2)$, perlindungan sosial $(-2)$ dan P2(-1) masing-masing adalah 1,414743; 2,335613; 2,115067; dan 1,187118. Karena nilai VIF untuk masing-masing variabel pada model indeks kedalaman dan keparahan kemiskinan dibawah 10 maka dapat dikatakan bahwa model indeks kedalaman dan keparahan kemiskinan tidak mengandung multikolinearitas.

\section{Model Regresi Data Panel}

1. Indeks Kedalaman Kemiskinan

Berdasarkan penjelasan sebelumnya menunjukan bahwa model terbaik untuk indeks kedalaman kemiskinan yaitu fixed effect model dengan metode estimasi seemingly unrelated regression (SUR), dimana modelnya adalah sebagai berikut:

$$
\begin{array}{r}
\overline{P 1_{l t}}=\left(8,34-\alpha_{i}\right)-0,08 K \operatorname{Shtn}(-2)_{i t}-0,06 \operatorname{Pnddkn}(-2)_{i t} \\
-1,45 \operatorname{PrlinSosial}(-2)_{i t}+0,09 P 1(-1)_{i t}+\varepsilon_{i t}
\end{array}
$$

Bedasarkan hasil uji t pada bagian sebelumnya telah dijelaskan bahwa lagged kedua dari variabel belanja pemerintah menurut fungsi kesehatan tidak berpengaruh signifikan terhadap indeks kedalaman kemiskinan. Kemudian, secara statistiknya dapat dijelaskan bahwa setiap kanaikan 1 persen belanja pemerintah untuk fungsi kesehatan pada tahun 2015, maka akan memperkecil besarnya kesenjangan yang terjadi antara rata-rata pengeluaran dari masingmasing penduduk miskin dengan garis kemiskinan sebesar 0,0815 persen.

Dari hasil uji t pada yang sudah dijelaskan sebelumnya bahwa lagged kedua dari variabel belanja pemerintah menurut fungsi pendidikan berpengaruh signifikan terhadap indeks kedalaman kemiskinan. Kemudian, secara statistiknya dapat dijelaskan bahwa setiap kanaikan 1 persen belanja pemerintah untuk fungsi pendidikan pada tahun 2015, maka akan memperkecil besarnya kesenjangan yang terjadi antara rata-rata pengeluaran dari masing-masing penduduk miskin dengan garis kemiskinan sebesar 0,0551 persen.

Kemudian hasil uji t untuk lagged kedua dari variabel belanja pemerintah menurut fungsi perlindungan sosial berpengaruh signifikan terhadap indeks kedalaman kemiskinan. Kemudian, secara statistiknya dapat dijelaskan bahwa setiap kanaikan 1 persen belanja pemerintah untuk fungsi perlindungan sosial pada tahun 2015, maka akan memperkecil besarnya kesenjangan yang terjadi antara rata-rata pengeluaran dari masing-masing penduduk miskin dengan garis kemiskinan sebesar 0,1445 persen.

Dari hasil uji t pada yang sudah dijelaskan sebelumnya menunjukan bahwa lagged pertama dari variabel indeks kedalaman kemiskinan berpengaruh tidak signifikan terhadap indeks kedalaman kemiskinan. Kemudian, secara statistiknya dapat dijelaskan bahwa setiap kanaikan 1 persen kesenjangan rata-rata pengeluaran penduduk miskin pada tahun 2016, maka 
akan semakin memperbesar kesenjangan antara rata-rata pengeluaran dari masing-masing penduduk miskin dengan garis kemiskinan pada tahun 2017 sebesar 0,0889 persen.

2. Indek Keparahan Kemiskinan

Seperti yang telah dijelaskan sebelumnya, dimana model terbaik yang digunakan untuk menjelaskan indek keparahan kemiskinan yaitu fixed effect model dengan metode estimasi seemingly unrelated regression (SUR), dimana modelnya adalah sebagai berikut:

$$
\begin{gathered}
\widehat{P 2_{i t}}=\left(3,62-\alpha_{i}\right)-0,06 \operatorname{Kshtn}(-2)_{i t}-0,04 P n d d k n(-2)_{i t}-0,07 \operatorname{PrlinSosial}(-2)_{i t} \\
+0,09 P 2(-1)_{i t}+\varepsilon_{i t}
\end{gathered}
$$

Bedasarkan hasil uji t yang telah dilakukan, maka dapat dijelaskan bahwa lagged kedua dari variabel belanja pemerintah menurut fungsi kesehatan berpengaruh signifikan terhadap indeks keparahan kemiskinan. Kemudian, secara statistiknya dapat dijelaskan bahwa setiap kanaikan 1 persen belanja pemerintah untuk fungsi kesehatan pada tahun 2015, maka akan memperkecil besarnya kesenjangan pengeluaran yang terjadi antara penduduk miskin sebesar 0,0603 persen.

Dari hasil uji t pada yang sudah dijelaskan sebelumnya bahwa lagged kedua dari variabel belanja pemerintah menurut fungsi pendidikan berpengaruh signifikan terhadap indeks keparahan kemiskinan. Kemudian, secara statistiknya dapat dijelaskan bahwa setiap kanaikan 1 persen belanja pemerintah untuk fungsi pendidikan pada tahun 2015, maka akan memperkecil besarnya kesenjangan pengeluaran yang terjadi antara penduduk miskin sebesar 0,0361 persen.

Kemudian hasil uji t untuk lagged kedua dari variabel belanja pemerintah menurut fungsi perlindungan sosial berpengaruh signifikan terhadap indeks keparahan kemiskinan. Kemudian, secara statistiknya dapat dijelaskan bahwa setiap kanaikan 1 persen belanja pemerintah untuk fungsi perlindungan sosial pada tahun 2015, maka akan memperkecil besarnya kesenjangan pengeluaran yang terjadi antara penduduk miskin sebesar 0,0733 persen.

Dari hasil uji t pada yang sudah dijelaskan sebelumnya menunjukan bahwa lagged pertama dari variabel indeks keparahan kemiskinan berpengaruh tidak signifikan terhadap indeks keparahan kemiskinan. Kemudian, secara statistiknya dapat dijelaskan bahwa setiap kanaikan 1 persen kesenjangan pengeluaran antara penduduk miskin pada tahun 2016, maka akan semakin memperbesar kesenjangan pengeluaran antara penduduk miskin pada tahun 2017 sebesar 0,0938 persen.

\section{KESIMPULAN}

Kesimpulannya adalah pemerintah provinsi Papua belum mampu dalam menurunkan persentase penduduk miskin. Namun, baru mampu menurunkan gap antara pengeluaran perkapita penduduk miskin dengan garis kemiskinan, dan juga mengurangi ketimpangan pengeluaran perkepita diantara penduduk miskin. Kemudian, disarankan kepada pemerintah provinsi Papua agar dapat mengawasi dengan ketat setiap unit yang memiliki tanggung jawab dalam penggunaan dana belanja pemerintah menurut fungsi kesehatan, pendidikan, dan perlindungan sosial.

\section{DAFTAR PUSTAKA}

Anderson, Edward, dkk. (2018). Does Government Spending Affect Income Poverty? A Meta-regression Analysis. World Development.

Baltagi, Badi H. (2005). Econometric Analysis of Panel Data $3^{\text {th }}$ edition. West Sussex: Jhon Wiley \& Sons.

Bappenas. (2005). Strategi Nasional Penanggulangan Kemiskinan. Jakarta: Bappenas.

BPS. (2018). Perhitungan dan Analisis Kemiskinan Makro dan Indonesia. Jakarta: BPS.

BPS. (2018). Indikator Pasar Tenaga Kerja Indonesia. Jakarta: BPS.

BPS. (2017). Papua Dalam Angka 2017. Papua: Badan Pusat Statistik.

Detik News. Apakah Kemiskinan di Papua Ikut Turun? Diakses 17 Februari 2019 melalui https://m.detik.com/news/kolom/d-4146501/apakah-kemiskinan-di-Papua-ikut-turun.

Direktorat Jenderal Perimbangan Keuangan. (2017). Realisasi Belanja Pemerintah Menurut Fungsi tahun 2017. Jakarta: Direktorat Jenderal Perimbangan Keuangan.

Koczan, Zsoka. (2016). Being Poor, Feeling Poorer: Inequality, Poverty And Poverty Perceptions In The Western Balkans. 
Merdeka. Bos BAPPENAS Beberkan Alasan Tingginya Angka Kemiskinan di Papua dan Maluku. Diakses 21 Janusari 2019 melalui https://www.merdeka.com/uang/bos-bappenas-beberkan-alasan-tingginyaangka-kemiskinan-di-papua-dan-maluku.html 